\title{
Interpreting SBUV smoothing errors: an example using the quasi-biennial oscillation
}

\author{
N. A. Kramarova ${ }^{1}$, P. K. Bhartia ${ }^{2}$, S. M. Frith ${ }^{1}$, R. D. McPeters ${ }^{2}$, and R. S. Stolarski ${ }^{3}$ \\ ${ }^{1}$ Science Systems and Applications Inc., Lanham, MD, USA \\ ${ }^{2}$ NASA Goddard Space Flight Center, Greenbelt, MD, USA \\ ${ }^{3}$ John Hopkins University, Baltimore, MD, USA
}

Correspondence to: N. A. Kramarova (natalya.a.kramarova@nasa.gov)

Received: 31 January 2013 - Published in Atmos. Meas. Tech. Discuss.: 19 March 2013

Revised: 26 July 2013 - Accepted: 30 July 2013 - Published: 22 August 2013

\begin{abstract}
The Solar Backscattered Ultraviolet (SBUV) observing system consists of a series of instruments that have been measuring both total ozone and the ozone profile since 1970. SBUV measures the profile in the upper stratosphere with a resolution that is adequate to resolve most of the important features of that region. In the lower stratosphere the limited vertical resolution of the SBUV system means that there are components of the profile variability that SBUV cannot measure. The smoothing error, as defined in the optimal estimation retrieval method, describes the components of the profile variability that the SBUV observing system cannot measure. In this paper we provide a simple visual interpretation of the SBUV smoothing error by comparing SBUV ozone anomalies in the lower tropical stratosphere associated with the quasi-biennial oscillation (QBO) to anomalies obtained from the Aura Microwave Limb Sounder (MLS). We describe a methodology for estimating the SBUV smoothing error for monthly zonal mean (mzm) profiles. We construct covariance matrices that describe the statistics of the inter-annual ozone variability using a $6 \mathrm{yr}$ record of Aura MLS and ozonesonde data. We find that the smoothing error is of the order of $1 \%$ between 10 and $1 \mathrm{hPa}$, increasing up to $15-20 \%$ in the troposphere and up to $5 \%$ in the mesosphere. The smoothing error for total ozone columns is small, mostly less than $0.5 \%$. We demonstrate that by merging the partial ozone columns from several layers in the lower stratosphere/troposphere into one thick layer, we can minimize the smoothing error. We recommend using the following layer combinations to reduce the smoothing error to about $1 \%$ : surface to $25 \mathrm{hPa}(16 \mathrm{hPa})$ outside (inside) of the narrow equatorial zone $20^{\circ} \mathrm{S}-20^{\circ} \mathrm{N}$.
\end{abstract}

\section{Introduction}

Measurements from the series of Solar Backscattered Ultraviolet (SBUV) instruments provide the longest record of satellite-based global ozone profiles, spanning the period from April 1970 through the present, except for a $5 \mathrm{yr}$ gap in the 1970s (McPeters et al., 2013). The SBUV instruments measure solar radiance in the ultraviolet spectral range between 250 and $340 \mathrm{~nm}$ backscattered by Earth's atmosphere and surface. The SBUV series includes the Nimbus-4 BUV, Nimbus-7 SBUV, and seven SBUV/2 instruments launched on NOAA operational satellites (NOAAs 09, 11, 14, 16, 17, 18, and 19). Data from all instruments have been reprocessed with the version 8.6 (v8.6) retrieval algorithm. In v8.6 the optimal estimation technique (Rodgers, 2000) is used to retrieve profiles of partial column ozone in defined pressure layers. The profiles are reported as ozone layer amounts (partial columns, DU) in 21 pressure layers. Consistency among SBUV instruments in v8.6 is achieved through radiance-level adjustments based on precise comparison of radiance measurements during the periods when instruments overlapped (DeLand et al., 2012). Despite the evolution in instrument design from the first BUV version to the modern SBUV/2 model, the fundamental features of the measurement technique remain the same (Bhartia et al., 2012), lending further consistency to the SBUV long-term record compared to those based on measurements using different instrument types and making the SBUV data preferable for long-term trend analysis. However, an understanding of the characteristics of the SBUV retrieval algorithm and related uncertainties is essential for proper interpretation of the data. The goal 
of this paper is to demonstrate the benefits and limitations of the SBUV retrieval algorithm and provide clear recommendations for SBUV data users.

In Sect. 2 we visually illustrate the SBUV smoothing error due to the limited vertical resolution. We then describe the methodology used to estimate the smoothing error for the SBUV monthly zonal mean (mzm) ozone profiles. We also introduce and analyze parameters that compose the smoothing error. In Sect. 3 we analyze the patterns of the SBUV smoothing error and make recommendations for best use of the data. In the last section we summarize our results. Hereafter we will use "SBUV" to refer to all instruments.

\section{Smoothing error}

The primary source of error in the SBUV retrieval algorithm, particularly in the troposphere and lower stratosphere, is the smoothing error due to the limited vertical resolution of the SBUV observing system (Bhartia et al., 2012). The smoothing error represents the difference between the retrieved profile and the true profile due to vertical smoothing by the retrieval algorithm and a potential bias introduced by a priori constraints (Rodgers, 2000). When the vertical resolution of the observing system is low, the retrieval algorithm relies on the a priori constraints, which could introduce biases into the retrieved profiles. Therefore the smoothing error depends on the vertical resolution of the observing system, the accuracy of the a priori data, and the magnitude and inter-level correlations of the natural ozone variability (Rodgers, 2000). For the first time with the v8.6 data set we include estimates of the smoothing error for the mzm SBUV data product, also newly available in v8.6.

\subsection{QBO Detection: a smoothing error example}

A vivid example of the smoothing error is the misrepresentation of the quasi-biennial oscillation (QBO) signal in the SBUV data in the lower tropical stratosphere (e.g., Hollandsworth et al., 1995). The QBO is a quasi-periodic oscillation between easterly and westerly regimes of the equatorial zonal wind, which in turn effects the distribution of chemical constituents, such as ozone, water vapor, and methane, due to induced circulation changes (e.g., Baldwin et al., 2001). The period of the QBO varies from 24 to 32 months with an average period of about 28 months. One of the pronounced features of the equatorial QBO is its downward vertical propagation with a rate of about $1 \mathrm{~km}$ per month (e.g., Baldwin et al., 2001).

Figure 1 shows time series of the deseasonalized mzm ozone anomalies obtained from NOAA17 SBUV/2 (black lines) and Aura Microwave Limb Sounder (MLS) (red lines) over the tropics $\left(0-5^{\circ} \mathrm{N}\right)$ for several layers in the stratosphere. The deseasonalized anomalies are calculated by subtracting seasonal cycles from each data set independently to remove systematical biases between the observing systems. There is a clear QBO signal in both data sets between 100 and $6.4 \mathrm{hPa}$, but the phases of the QBO signals are shifted. SBUV "sees" the same phase of the QBO at all layers, while MLS shows a vertical downward propagation of the QBO signal over time. Also, the amplitude of the QBO signal derived from MLS is larger compared to that derived from SBUV. Neither data set shows a QBO above $6.4 \mathrm{hPa}$. The magenta lines in the panels of Fig. 1 show the MLS anomalies convolved by the SBUV averaging kernels. The convolved MLS anomalies agree well with the SBUV anomalies, meaning that the differences in the original profiles are due solely to the differing vertical resolutions. This is particularly evident in layers below $16 \mathrm{hPa}$. For the layers between 100 and $6.4 \mathrm{hPa}$, the convolved MLS now shows the same QBO phase lag as the SBUV measurements. The difference between the deseasonalized MLS and SBUV anomalies shows the portion of ozone variability that the SBUV observing system cannot measure, and this quantity can be understood as the SBUV smoothing error.

We will now describe the methodology for estimating the smoothing error and introduce and analyze parameters that compose the smoothing error.

\subsection{Mathematical definition of smoothing error}

According to Rodgers (2000) smoothing error can be calculated as

$\mathbf{S}_{\mathrm{serr}}=(\mathbf{A}-\mathbf{I}) \cdot \mathbf{C} \cdot(\mathbf{A}-\mathbf{I})^{T}$,

where $\mathbf{I}$ is a unit matrix, $\mathbf{A}$ is a matrix that represents the sensitivity of the SBUV retrieval $\hat{\boldsymbol{x}}$ to the true state $\boldsymbol{x}: \mathbf{A}=$ $\partial \hat{\boldsymbol{x}} / \partial \boldsymbol{x}$; and $\mathbf{C}$ is the covariance matrix of an ensemble of states about the mean state, calculated as

$\mathbf{C}=\operatorname{cov}\left\{(\boldsymbol{x}-\overline{\boldsymbol{x}})(\boldsymbol{x}-\overline{\boldsymbol{x}})^{T}\right\}$.

In Eq. (2), $\boldsymbol{x}$ is a set of independent high-resolution ozone profiles that characterize the ozone variability.

In this representation, the resulting quantity $\mathbf{S}_{\text {serr }}$ is the smoothing error covariance matrix, which can be understood as an "error pattern" (Rodgers, 1990). $\mathbf{S}_{\text {serr }}$ is defined by two parameters: the SBUV A matrix and the covariance matrix C. In short, the A matrix shows how information from measurements and a priori are utilized in the retrieval algorithm and provides a measure of the resolution that can be achieved by the retrieval, while the $\mathbf{C}$ matrix provides information on the magnitudes and inter-layer correlations of the ozone variability. Before analyzing the smoothing errors, we consider each of these parameters separately. 

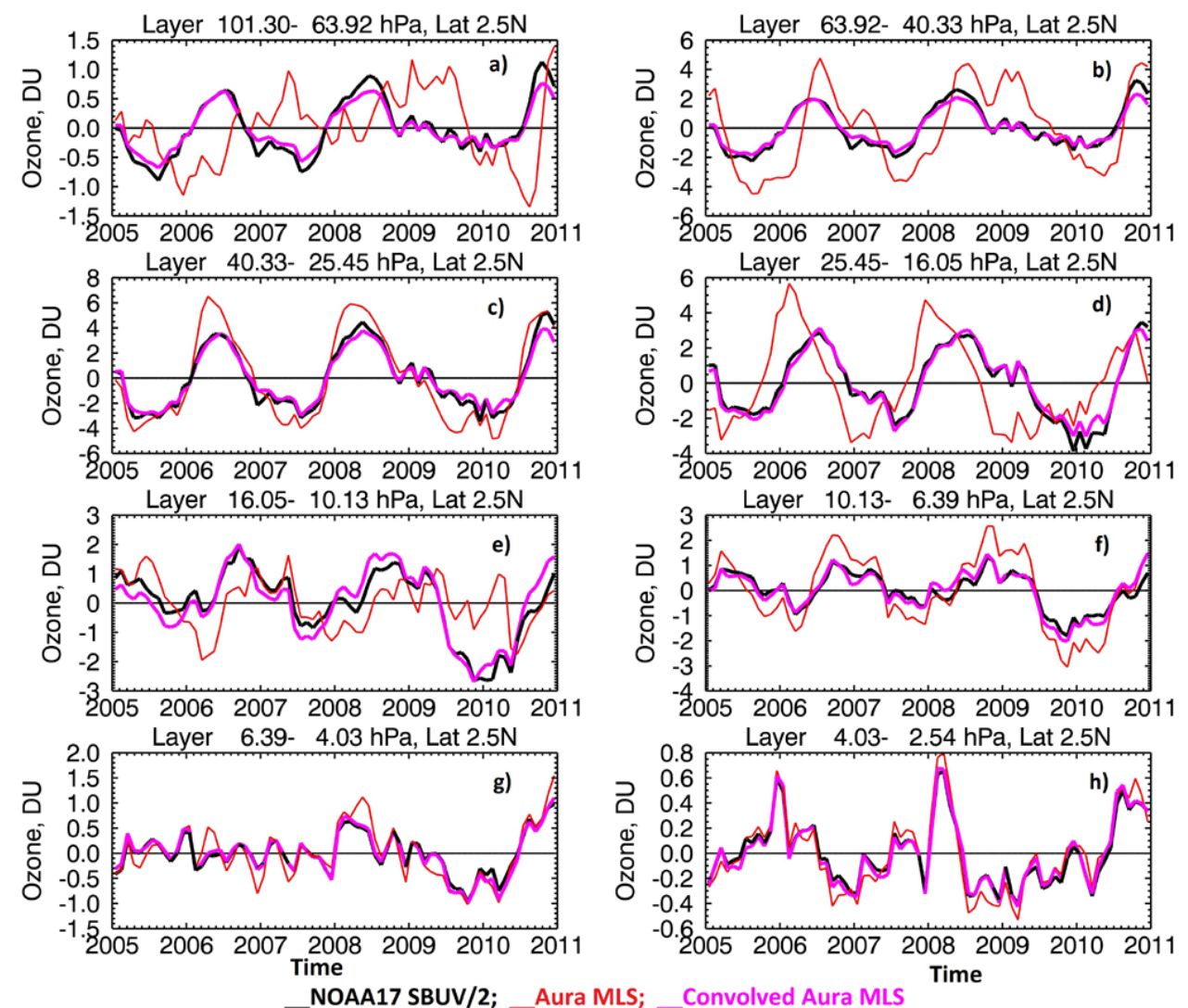

Fig. 1. Deseasonalized time series of the ozone mzm columns in the lower tropical stratosphere $\left(0-5^{\circ} \mathrm{N}\right)$. Black lines correspond to SBUV anomalies, red lines show MLS anomalies and magenta lines indicate convolved MLS anomalies. The MLS mixing ratio profiles were converted first to the partial ozone columns at the SBUV layers.

\subsection{SBUV A matrix}

\subsubsection{SBUV version 8.6 algorithm}

In this section we outline the main features of the SBUV v8.6 retrieval algorithm, fully described by Bhartia et al. (2012), that are relevant to the present study. In v8.6 the optimal estimation technique (Rodgers, 2000) is used to retrieve ozone profiles as partial ozone columns (DU per layer) at 80 pressure layers plus a top layer above $0.1 \mathrm{hPa}$. The seasonal ozone climatology, derived from Aura MLS and ozonesonde observations (McPeters and Labow, 2012), is used by the retrieval algorithm as the a priori information. The a priori covariance matrix $\mathbf{S}_{\mathrm{a}}$ is constructed assuming that the variance at each layer is equal to a constant fraction of the a priori, and that adjacent layers are highly correlated: $\mathbf{S}_{\mathrm{a}}(\mathrm{i}, \mathrm{j})=$ $\sigma^{2} \boldsymbol{x}_{\mathrm{a}}(i) \boldsymbol{x}_{\mathrm{a}}(j) e^{-|i-j| / N_{\mathrm{c}}}$, where $\boldsymbol{x}_{\mathrm{a}}$ is the SBUV a priori; $i$ and $j$ are layer indices; $\sigma^{2}$ is the fractional ozone variance, and $N_{\mathrm{c}}$ is a number of adjacent layers that are highly correlated. We set $\sigma=0.5$ and $N_{\mathrm{c}}=12(\sim 10 \mathrm{~km})$ in the v8.6 algorithm. The algorithm uses the same a priori covariance matrix for all latitude bins and seasons. The measurement error covariance matrix $\mathbf{S}_{\mathrm{e}}$ is constructed as a diagonal matrix with the diagonal elements $\sigma_{\mathrm{e}}=0.43 \mathrm{~N}$ value, where $N$ value is the logarithm of the backscattered radiance to solar irradiance ratio: $N_{\text {value }}=-100 \log _{10} I / I_{0}$ (see Bhartia et al., 2012).

In v8.6 ozone profiles are reported as partial ozone columns (DU per layer) at 20 pressure layers (plus a top layer above $0.1 \mathrm{hPa}$ ) by combining ozone in every 4 retrieved layers. The 81 layers ( 80 plus a top layer) are needed to increase the accuracy of the forward model calculations, but the vertical resolution of the SBUV measurement system is much coarser, thus it is reasonable to report data at thicker layers. All correlative quantities, such as a priori, Jacobian, A matrix, etc., are reported at the same 20 layers. The total ozone columns are calculated as sums of the partial ozone columns at all 21 layers.

For the first time, v8.6 SBUV mzm ozone profiles have been released as a primary product for use in the long-term time series analysis. The mzm profiles are calculated in $5^{\circ}$ latitudinal bins with midpoints starting at $87.5^{\circ} \mathrm{S}$ by simply averaging individual profiles in the specific month and latitude bin. The smoothing errors are calculated for the mzm profiles. 


\subsubsection{SBUV averaging kernels}

The SBUV A matrix has dimensions of number of layers by number of layers, though the top layer is not included, so the dimensions are 20 by 20 . The $\mathbf{A}$ matrix shows how information from measurements and a priori are utilized during the retrieval process. A column of the $\mathbf{A}$ matrix at a given layer $l$ (where $l$ is a layer index from 1 to 20) gives the response of the retrieval at each layer to a delta-function perturbation of ozone amount in layer $l$; a row of the $\mathbf{A}$ matrix at a given layer $l$ indicates the sensitivity of the retrieved ozone at layer $l$ to delta-function perturbations of ozone at each layer (Rodgers, 2000). Rows of the A matrices are called the averaging kernels (AK), while columns are referred to as the response functions. Hereafter, we will follow Rodgers terminology and use a term "AK" to refer to rows of the A matrix.

The shape of the AK for each layer describes the vertical resolution of the observing system at that layer. An idealized AK for a defined layer would have a $\delta$-function shape with an integrated value of about one, and a width within the boundary of the layer. Limitations of the resolution are indicated when the AK peak is very broad and displaced in altitude (Rodgers, 2000).

The A matrix is relevant to profiles of partial ozone columns in units of DU per layer, but the shapes of averaging kernels (rows of A matrix) are different from the well-known bell shape. To simplify visual analysis, we show rows of normalized $\mathbf{A}_{\mathrm{n}}$ matrix in Fig. 2. The normalization is done as follows:

$\mathbf{A}_{\mathrm{n}}(i, j)=\mathbf{A}(i, j) \cdot \boldsymbol{x}_{\mathrm{a}}(j) \boldsymbol{x}_{\mathrm{a}}(i)$,

where $\boldsymbol{x}_{\mathrm{a}}$ is the SBUV a priori profile, and $i$ and $j$ are layer indices from 1 to 20 . This normalized $\mathbf{A}_{\mathrm{n}}$ matrix is applicable to the ozone profiles expressed as a fraction from the a priori. We need to emphasize that for the smoothing error calculations the original A matrices have been used.

Figure 2 shows typical normalized SBUV AK for the northern midlatitudes and tropics. The normalized SBUV AK for layers between 16 and $1 \mathrm{hPa}$ have sharp maxima at nominal altitudes. This means that the SBUV algorithm is capable of accurately retrieving layer ozone amounts in this vertical range. The normalized AK for layers below $16 \mathrm{hPa}$ (and above $1 \mathrm{hPa}$ ) have broad peaks, which are shifted upward (downward) from the layer nominal altitude, showing that the retrievals are more sensitive to ozone changes at higher (lower) layers. In these vertical ranges, the SBUV retrievals contain less information about the true ozone changes at these layers, and the retrieval algorithm relies on the a priori. In the tropics the shapes of the normalized AK for layers below $10 \mathrm{hPa}$ differ from those at midlatitudes (see Fig. 2). Peaks of the normalized tropical AK for layers below $25 \mathrm{hPa}$ are shifted upward with the maximum around $25 \mathrm{hPa}$, and the amplitudes of the normalized AK are significantly reduced below $60 \mathrm{hPa}$. Thus, compared to midlatitudes, the tropical retrievals are less sensitive to ozone changes in the lower stratosphere and troposphere and heavily rely on a priori information.

The number of independent pieces of information available from measurements is given by the diagonal elements of the A matrix, known as degrees of freedom for signal (DFS) (Rodgers, 2000). Note that the diagonal elements of $\mathbf{A}$ and $\mathbf{A}_{\mathrm{n}}$ are the same. The sum of all diagonal elements of the $\mathbf{A}$ matrix - the total DFS - varies from 3.7 to 6.9 out of the 6-9 wavelengths used in the retrieval algorithm depending on the solar zenith angle (SZA). The retrieval algorithm uses only 6 wavelengths for small SZA and 9 wavelengths for high SZA (Bhartia et al., 2012). As a result the DFS is larger for higher SZA.

Each diagonal element of the A matrix in turn indicates the DFS for the individual layer. Figure 3 shows the layer DFS for the northern midlatitudes in winter and summer (blue and green lines, respectively) and for the tropics (red line). Peaks of the layer DFS occur between 25 and $1 \mathrm{hPa}$, where the layer DFS are about 0.5. The total DFS is larger in northern midlatitudes in winter (5.5) and decreases slightly in summer (5.0). The increase of total DFS in winter is due to the higher SZAs and subsequent increased vertical resolution in the upper layers. The layer DFS also increases in the upper layers above $1 \mathrm{hPa}$ when the satellite approaches the terminator and SZA rapidly increases. In the tropics, SZA does not significantly change with season, and the A matrices are similar for all seasons. The shapes of the layer DFS in the tropics and midlatitudes in summer (red and green lines in Fig. 3) are very similar above $25 \mathrm{hPa}$, but below $40 \mathrm{hPa}$ the tropical layer DFS abruptly decreases, due to fewer wavelengths used to retrieve ozone at small SZAs and the higher altitude of the ozone peak in the tropics. The longest wavelength used in the retrieval varies from $302 \mathrm{~nm}$ at small SZA to $317.5 \mathrm{~nm}$ at large SZA to minimize effects of absorbing aerosols.

Since the diagonal elements $d_{s}$ of the A matrix give the DFS per layer, one can estimate the vertical resolution as the number of layers per degree of freedom $1 / d_{s}$ (Rodgers, 2000). The AK show that the vertical resolution of the SBUV algorithm is about $6-7 \mathrm{~km}$ near $3 \mathrm{hPa}$, decreasing to $15 \mathrm{~km}$ in the troposphere (Bhartia et al., 2012).

\subsection{Ozone mzm covariance matrix}

The second parameter that defines the smoothing error is the covariance matrix $\mathbf{C}$, which is used to represent the statistics of ozone variability. We are computing the smoothing error for SBUV mzm profiles, and therefore we need to construct appropriate covariance matrices that characterize the typical year-to-year variability of the ozone mzm profiles for each latitude bin.

Aura MLS profiles provide the high vertical and spatial resolution needed to obtain the statistics of ozone variability (e.g., Froidevaux et al., 2008). In the troposphere, we extend MLS profiles by merging them with ozonesonde mzm profiles, obtained from the ensemble of 48 stations listed in 

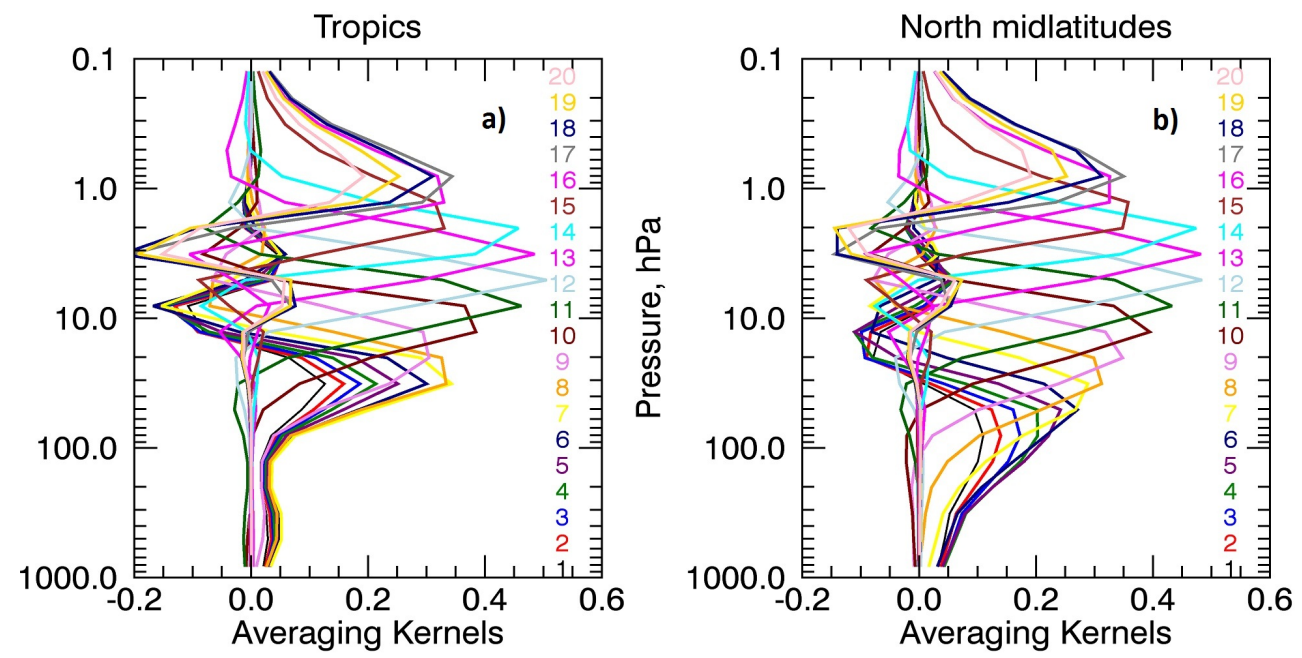

Fig. 2. Typical SBUV averaging kernels for (a) the tropics and (b) northern middle latitudes. Different colors correspond to individual layers, and layer numbers are indicated on the right.

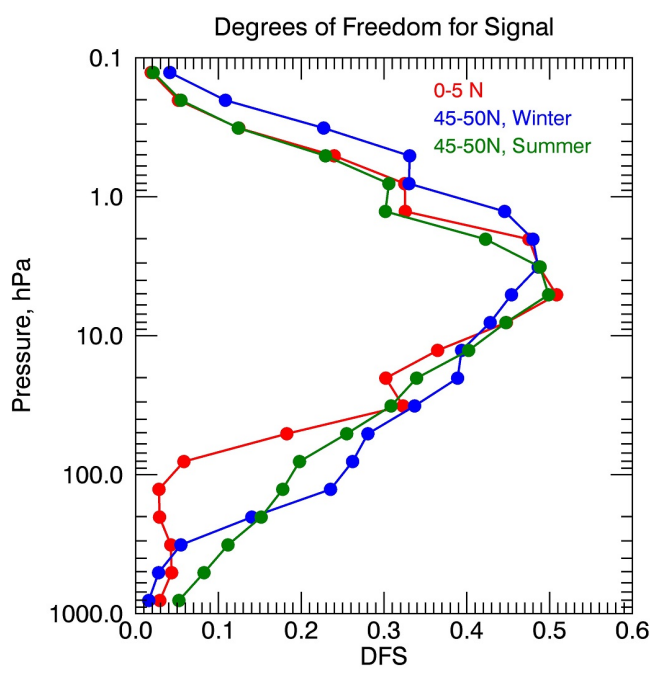

Fig. 3. Typical profiles of layer DFS for the northern midlatitudes in summer (green line), in winter (blue line) and for the tropics (red line). Profiles from NOAA 17, January and July 2007. The connecting lines between the data points have no physical meaning and are drawn only to guide the eye.

Table 1. We construct MLS mzm time series over the $6 \mathrm{yr}$ period from January 2005 to December 2010 for each $5^{\circ}$ zonal bin using version 3.3 daytime-only MLS profiles with SZAs less than $83^{\circ}$. Additional filtering is applied according to recommendations outlined in the MLS version 3.3 users guide (Livesey et al., 2011). We distribute sonde data by $10^{\circ}$ latitude bins following the guidance provided by McPeters and Labow (2012) to account for limited sampling in some latitude bins. The $10^{\circ}$ zonal sonde data for each month and altitude level have been interpolated to the $5^{\circ}$ latitude scale. Data from many sonde stations were not available during the Aura
MLS period, so we instead used sonde data over the $6 \mathrm{yr}$ period from January 2000 to December 2005. The sonde mzm time series were smoothed using a 3 month moving average to reduce noise. Both MLS and sonde profiles were converted into ozone partial columns at SBUV pressure layers.

For each month and latitude bin we merge sonde and Aura MLS mzm profiles in layers 5, 6 and 7 (between 160 and $40 \mathrm{hPa}$ ) using a proportional 75,50 and $25 \%$ weighting for the sonde data in layers 5,6 and 7. Since the SBUV technique depends on backscattered solar radiation, measurements at high latitudes are not possible in winter months. Thus we estimate the statistics of the ozone variability at high latitudes using data only in months when SBUV ozone measurements exist (see Table 2).

The covariance matrices $\mathbf{C}$ for each $5^{\circ}$ latitude bin have been calculated by employing Eq. (2), and are included in the SBUV mzm data files. The resulting covariance matrix $\mathbf{C}$ for each latitude bin is a matrix with dimensions of number of layers by number of layers (20 by 20 ; top layer not included), with the diagonal elements equal to the squares of the standard deviations of mzm merged MLS/sonde profiles. The calculated covariance matrices $\mathbf{C}$ represent the variability of the merged MLS/sonde data about their mean. We assume that the MLS and sonde measurement error covariance matrices $\mathbf{S}_{\mathrm{e}}$ are small compared to $\mathbf{C}$, thus the $\mathbf{C}$ matrix represents natural ozone variability. However, we should note that to compute the actual smoothing error we need to know the variability of the "true" ozone profiles about the SBUV a priori. The difference between the estimated and "true" variability will add additional errors in smoothing error calculations, but since the "true" state is not known these errors cannot be estimated.

Figure 4 shows the square roots of the diagonal elements of the covariance matrices for three different latitude bins as 
Table 1. List of ozonesonde stations used to estimate inter-annual ozone variability for smoothing error calculations over the time period from 1 January 2000 to 31 December 2005.

\begin{tabular}{|c|c|c|c|c|}
\hline $\begin{array}{l}\text { Latitude } \\
\text { bin }\end{array}$ & Station & Latitude & Longitude & $\begin{array}{r}\text { Number of } \\
\text { profiles }\end{array}$ \\
\hline $80-90^{\circ} \mathrm{S}$ & South Pole & -89.9 & 24.8 & 347 \\
\hline $70-80^{\circ} \mathrm{S}$ & Neumayer & -70.7 & -8 & 425 \\
\hline \multirow[t]{3}{*}{$60-70^{\circ} \mathrm{S}$} & Davis & -68.6 & 79.9 & 61 \\
\hline & Marambio & -64.2 & -56.7 & 121 \\
\hline & Syowa & -69 & 39.58 & 397 \\
\hline $50-60^{\circ} \mathrm{S}$ & Macquarie & -54.5 & 158.9 & 248 \\
\hline $40-50^{\circ} \mathrm{S}$ & Lauder & -45 & 169.6 & 337 \\
\hline $30-40^{\circ} \mathrm{S}$ & Laverton & -37.8 & 144.7 & 257 \\
\hline \multirow{2}{*}{$20-30^{\circ} \mathrm{S}$} & Irene & -25.2 & 28.18 & 170 \\
\hline & Reunion & -21 & 55.48 & 175 \\
\hline \multirow[t]{3}{*}{$10-20^{\circ} \mathrm{S}$} & Reunion & -21 & 55.48 & 175 \\
\hline & Samoa & -14.2 & -170 & 205 \\
\hline & Fiji & -17.4 & 178.3 & 154 \\
\hline \multirow[t]{5}{*}{$0-10^{\circ} \mathrm{S}$} & Ascension Island & -7.58 & -14.2 & 259 \\
\hline & Java & -7.5 & 112.6 & 191 \\
\hline & Nairobi & -1.27 & 36.8 & 343 \\
\hline & Natal & -5.42 & -35.3 & 241 \\
\hline & San Cristobal & -0.92 & -89.6 & 216 \\
\hline \multirow[t]{4}{*}{$0-10^{\circ} \mathrm{N}$} & Cotonou & 6.21 & 2.23 & 39 \\
\hline & Kuala Lumpur & 2.73 & 101.7 & 148 \\
\hline & Paramaribo & 5.81 & -55.2 & 261 \\
\hline & Trivandrum & 8.29 & 76.95 & 45 \\
\hline \multirow[t]{2}{*}{$10-20^{\circ} \mathrm{N}$} & Hilo & 19.72 & -155 & 313 \\
\hline & Poona & 18.53 & 73.85 & 25 \\
\hline \multirow[t]{4}{*}{$20-30^{\circ} \mathrm{N}$} & Hanoi & 21.02 & 105.8 & 23 \\
\hline & Hilo & 19.72 & -155 & 313 \\
\hline & Kagoshima & 31.55 & 130.5 & 246 \\
\hline & Naha & 26.2 & 127.6 & 245 \\
\hline \multirow[t]{5}{*}{$30-40^{\circ} \mathrm{N}$} & Boulder & 40.02 & -105 & 291 \\
\hline & Huntsville & 34.72 & -86.6 & 228 \\
\hline & Madrid & 40.46 & -3.65 & 152 \\
\hline & Tateno & 36.05 & 140.1 & 333 \\
\hline & Wallops & 37.93 & -75.4 & 241 \\
\hline \multirow[t]{4}{*}{$40-50^{\circ} \mathrm{N}$} & Canada (Yarmouth, Kelowna) & 47 & -92 & 138 \\
\hline & Hohenpeisenberg & 47.8 & 11.02 & 755 \\
\hline & Payerne & 46.8 & 6.95 & 904 \\
\hline & Sapporo & 43.05 & 141.3 & 275 \\
\hline \multirow[t]{4}{*}{$50-60^{\circ} \mathrm{N}$} & Edmonton & 53.55 & -114 & 269 \\
\hline & Goose & 53.32 & -60.3 & 266 \\
\hline & Lindenberg & 52.21 & 14.12 & 288 \\
\hline & Uccle & 50.8 & 4.35 & 823 \\
\hline \multirow[t]{3}{*}{$60-70^{\circ} \mathrm{N}$} & Churchill & 58.75 & -94 & 221 \\
\hline & Lerwick & 60.13 & -1.18 & 233 \\
\hline & Sodankylä & 67.39 & 26.65 & 409 \\
\hline \multirow[t]{4}{*}{$70-80^{\circ} \mathrm{N}$} & Ny-Ålesund & 78.93 & 11.88 & 521 \\
\hline & Resolute & 74.72 & -94.9 & 148 \\
\hline & Scoresbysund & 70.49 & -21.9 & 188 \\
\hline & Thule & 76.53 & -68.7 & 66 \\
\hline $80-90^{\circ} \mathrm{N}$ & Alert & 82.5 & -62.3 & 300 \\
\hline
\end{tabular}

a percent of the mean annual SBUV a priori at each latitude (also see Fig. S1 in Supplement, which shows profiles for all latitude bins). Standard deviations vary between 2 and $15 \%$, increasing in the troposphere and lower stratosphere. However, in the tropical lower stratosphere between 100 and

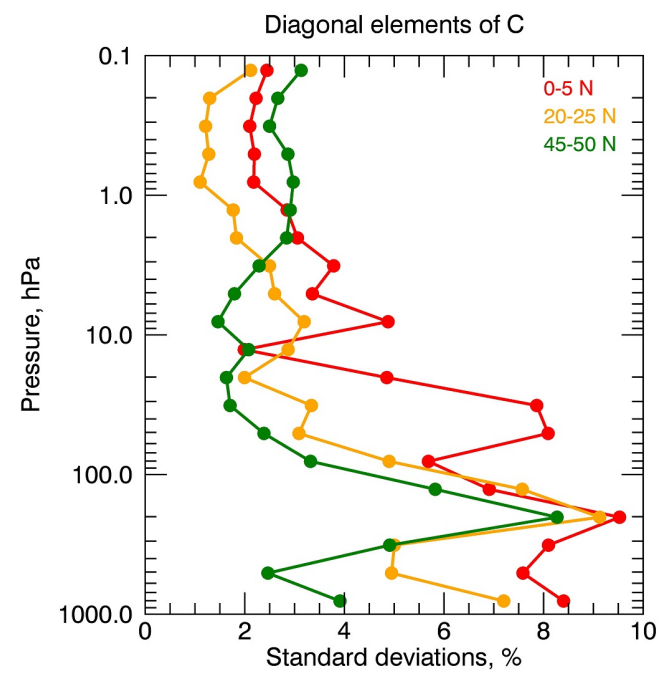

Fig. 4. Vertical profiles of the square roots of diagonal elements of the covariance matrix for three latitude bins as percent relative to the a priori. These quantities are equal to the standard deviations of the mzm profiles.

$10 \mathrm{hPa}$ standard deviations are larger compared to mid and high latitudes due to the QBO.

Off-diagonal elements of $\mathbf{C}$ reveal correlations among the layers. Figure S2 in the Supplement shows correlation patterns of $\mathbf{C}$ for four different latitude bins. If the correlation between any two layers is high, the corresponding offdiagonal elements will also be large, and vice versa. We do not analyze off-diagonal elements of $\mathbf{C}$ here, because a simple sensitivity test in which the smoothing error was calculated with the off-diagonal elements of covariance matrices set to zero showed that in our case the off-diagonal elements had a very small effect on the smoothing error values. For this reason, the mismatch of the time periods between MLS (2005-2010) and sonde measurements (2000-2005) used to construct the covariance matrices $\mathbf{C}$ should not affect the smoothing error calculations, because only the off-diagonal elements of $\mathbf{C}$, which indicate the inter-level correlation, are sensitive to the time mismatch. We expect the ozone variances (presented by the diagonal elements of $\mathbf{C}$ ) over the two considered 6 yr time periods to be very similar. Nevertheless off-diagonal elements of the covariance matrices $\mathbf{C}$ are included in the computation of the smoothing error.

\section{Application of smoothing error concept to SBUV data analysis}

For each SBUV mzm profile the smoothing error covariance matrix $\mathbf{S}_{\text {serr }}$ was calculated using Eq. (1). All elements (diagonal and off-diagonal) of the $\mathbf{C}$ and $\mathbf{A}$ matrices are included in the computation of the smoothing error. The diagonal elements of $\mathbf{S}_{\text {serr }}$ represent the error variances of the elements of the SBUV mzm profile $\hat{\boldsymbol{x}}$, and the off-diagonal elements 
Table 2. Months of the year for high latitude regions when the SBUV measurements are not possible (or very limited) due to high SZA (polar night conditions). Note, between $60^{\circ} \mathrm{S}$ and $60^{\circ} \mathrm{N}$ the SBUV obtains measurements over the whole year. The orbit of the SBUV satellites and the geometry of the measurement does not allow for sampling atmospheric ozone poleward of $82^{\circ}$.

\begin{tabular}{lllllllll}
\hline $\begin{array}{l}\text { Latitude } \\
\text { bins }\end{array}$ & $80-75^{\circ} \mathrm{S}$ & $70-75^{\circ} \mathrm{S}$ & $65-70^{\circ} \mathrm{S}$ & $60-65^{\circ} \mathrm{S}$ & $60-65^{\circ} \mathrm{N}$ & $65-70^{\circ} \mathrm{N}$ & $70-75^{\circ} \mathrm{N}$ & $75-80^{\circ} \mathrm{N}$ \\
\hline $\begin{array}{l}\text { Missed } \\
\text { Months }\end{array}$ & $\begin{array}{l}\text { Apr- } \\
\text { Sep }\end{array}$ & $\begin{array}{l}\text { May- } \\
\text { Aug }\end{array}$ & $\begin{array}{l}\text { May- } \\
\text { Jul }\end{array}$ & $\begin{array}{l}\text { Jun- } \\
\text { Jul }\end{array}$ & Dec & $\begin{array}{l}\text { Nov- } \\
\text { Jan }\end{array}$ & $\begin{array}{l}\text { Nov- } \\
\text { Feb }\end{array}$ & $\begin{array}{l}\text { Oct- } \\
\text { Feb }\end{array}$ \\
\hline $\begin{array}{l}\text { \# of } \\
\text { missed } \\
\text { month }\end{array}$ & 6 & 4 & 3 & 2 & 1 & 3 & & \\
\hline
\end{tabular}

of $\mathbf{S}_{\mathrm{serr}}$ indicate the inter-level error correlations (Rodgers, 1990). When the off-diagonal elements of $\mathbf{S}_{\text {serr }}$ indicate that the errors are highly correlated, then we have more information about $\boldsymbol{x}$ (Rodgers, 1990) and the errors are expected to be smaller.

It is not easy to analyze and interpret errors represented in terms of the smoothing error covariance matrix $\mathbf{S}_{\text {serr }}$ (see Fig. S3 in Supplement). To simplify the analysis, we ignore inter-level correlation and assume that the square roots of the diagonal elements of $\mathbf{S}_{\text {serr }}$ represent the smoothing errors for individual layers. We also calculated eigenvectors of $\mathbf{S}_{\text {serr }}$ and found that in our case diagonal elements provide a reasonable estimation of the layer smoothing errors. Figure S4 in the Supplement shows the five first eigenvectors of $\mathbf{S}_{\mathrm{serr}}$. The smoothing error for total ozone is calculated as a square root of the sum of all elements of $\mathbf{S}_{\text {serr }}$ (including off-diagonal elements). In the mzm SBUV files we report the smoothing error as a percent of the retrieved layer ozone amount.

\subsection{Profile and total ozone smoothing error}

Figure 5 shows profiles of the smoothing error at $45-50^{\circ} \mathrm{N}$ in winter and summer (blue and green lines, respectively) and at $0-5^{\circ} \mathrm{N}$ (red line). Figures S5-S7 in the Supplement also demonstrate profiles of the smoothing errors for different seasons and latitude bins. In the stratosphere between 10 and $1 \mathrm{hPa}$, where the SBUV vertical resolution is the highest, the smoothing errors are of the order of 1-2\%. Larger smoothing errors (in some cases as large as 15-20\%) occur in the troposphere. Errors also increase up to $5 \%$ in the mesosphere above $1 \mathrm{hPa}$.

In the midlatitudes the layer smoothing errors vary with season due to seasonal changes of the AK. It is important to remember that the covariance matrix is a function of latitude only. Thus, all temporal changes in the smoothing errors are caused by the temporal changes in the AK. Overall, there is a very good consistency between seasonal changes of the layer DFS and smoothing error (Figs. 3 and 5). At those layers where the DFS is larger the corresponding smoothing errors are smaller and vice versa.

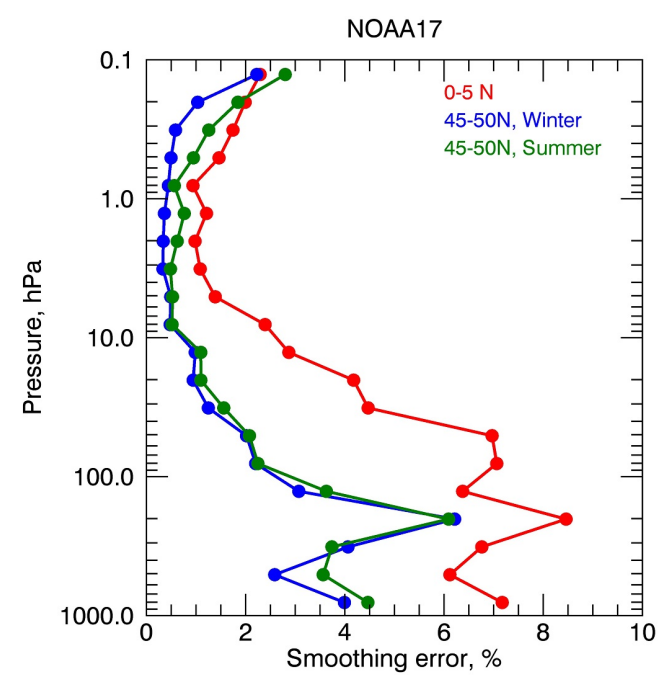

Fig. 5. Typical profiles of SBUV smoothing error (\% from the mean a priori profile) for the northern midlatitudes in summer (green line), in winter (blue line) and for the tropics (red line). Profiles from NOAA 17, January and July 2007.

In the tropical stratosphere below $10 \mathrm{hPa}$, the layer smoothing errors are notably greater compared to the mid and high latitudes. We previously noted a decrease of the tropical layer DFS below $40 \mathrm{hPa}$. However, the smoothing error increases in the tropics primarily because of the larger inter-annual ozone variability in the tropical lower stratosphere associated with the QBO (see Fig. 4). In very few cases, for example in layers $6(100-63 \mathrm{hPa})$ and $10(16-$ $10 \mathrm{hPa}$ ) in the tropics, $10^{\circ} \mathrm{S}-10^{\circ} \mathrm{N}$, the smoothing errors are larger than the estimated ozone standard deviations (square roots of the diagonal elements of $\mathbf{C}$, Fig. 4). This is a limitation of our approach considering only the diagonal elements of $\mathbf{S}_{\text {serr }}$ and ignoring inter-level error correlations to estimate the layer smoothing errors.

Figure 6 shows time series of the total ozone smoothing error at $0-5^{\circ} \mathrm{N}$ and $45-50^{\circ} \mathrm{N}$. The total ozone smoothing error is calculated as a square root of the sum of all elements of $\mathbf{S}_{\text {serr }}$. Smoothing errors for the total ozone vary between $0.2-1.2 \%$. The off-diagonal elements of the $\mathbf{A}$ matrix play 
a significant role in defining the error range for total ozone. The total ozone errors notably increase when the satellites approach the terminator and SZA increases. This might seem contradictory, since the total DFS increases with increasing SZA due to the larger number of wavelengths used to retrieve ozone at high SZA, implying that we have more information from measurements. But the increase in total DFS is related to increased sensitivity in the upper layers, not in the lower layers, which dominate total ozone. In the lower layers the diagonal elements of A change little with the SZA, while the off-diagonal elements of $\mathbf{A}$ in turn are very sensitive to SZA changes and decrease as SZA increases. Thus, as a result the total ozone smoothing error increases with increasing SZA.

We confirmed these results by running a sensitivity test in which the smoothing error was calculated with the offdiagonal elements of $\mathbf{A}$ set to zero. The changes to the layer smoothing error were small, but the total ozone smoothing errors increased by a factor of 5-10 (up to 2-6\%) when offdiagonal elements of $\mathbf{A}$ were ignored.

\subsection{Recommendations for reducing the smoothing error}

As we demonstrated, the smoothing error in the lower stratosphere and troposphere can be significant and caution should be taken when comparing SBUV ozone profiles with highly resolved profiles. One approach to such comparisons is to convolve the highly resolved profile with the SBUV AK as shown in Fig. 1. The profile with finer vertical resolution should be degraded first onto the SBUV vertical scale and then convolved using the SBUV A matrix (Rodgers and Connor, 2003):

$\boldsymbol{x}_{\text {smoothed }}=\boldsymbol{x}_{\mathrm{a}}+\mathbf{A} \cdot\left(\boldsymbol{x}_{\mathrm{hr}}-\boldsymbol{x}_{\mathrm{a}}\right)$,

where $\boldsymbol{x}_{\mathrm{hr}}$ is the highly resolved profile converted to partial ozone columns and degraded to the SBUV vertical scale.

However, it is not clear how to convolve a highly resolved profile that covers only a part of the atmosphere. For example, lidar instruments typically measure ozone only between 20 and $50 \mathrm{~km}$, while the SBUV A matrix is supposed to be applied to the entire profile from the surface to top of the atmosphere. Liu et al. (2010) use MLS partial ozone columns complemented with Ozone Monitoring Instrument (OMI) retrievals below $215 \mathrm{hPa}$ to convolve MLS ozone profiles with OMI AK. But different observing systems have different sensitivities and vertical resolutions, and this approach might "project" the uncertainties of one observing system onto the other. Alternatively, the missing part of the profile could be assumed to be equal to the a priori, and then the term in brackets in Eq. (4) will be equal to zero in the vertical range where measurements are missing.

We tested these two approaches to convolving Aura MLS profiles (which cover the vertical range between 250 and $0.1 \mathrm{hPa}$ ) with the SBUV A matrix. In the first approach we extended MLS profiles below $250 \mathrm{hPa}$ with SBUV retrievals,
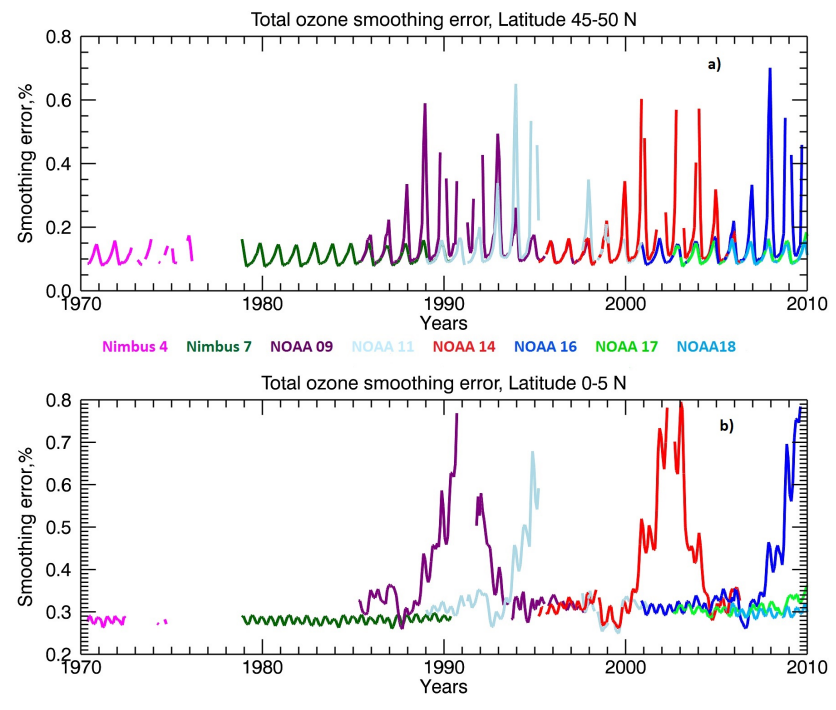

Fig. 6. Time series of the SBUV smoothing error for mzm total ozone column. (a) for $40-45^{\circ} \mathrm{N}$ latitude zone and (b) for $0-5^{\circ} \mathrm{N}$ latitude zone. Different colors correspond to individual SBUV instruments.

and in the second approach we used the SBUV a priori profiles. We found that the difference between the two convolved profiles is fairly small (less $0.5 \%$ ) in the vertical range between 25 and $1 \mathrm{hPa}$, where the SBUV vertical resolution is the highest. At the same time, between 250 and $25 \mathrm{hPa}$, where the SBUV vertical resolution is limited, the difference between the two approaches was up to $\pm 3 \%$. We found even larger differences (up to $\pm 10 \%$ ) between the two approaches when we convolved lidar profiles. These differences reflect an additional source of uncertainty in the convolved profile.

To avoid these complications, we propose merging several layers in the lower stratosphere/troposphere, where the smoothing errors are large, into a single thick combined layer. If the thickness of the combined layer is close to the vertical resolution of the measured signal, then the smoothing error for the combined layer will decrease. The DFS of the combined layer is equal to the sum of the "parent" layer DFS. The analysis of the AK (see Fig. 2) indicates a limitation of the retrievals below $25 \mathrm{hPa}$ (below $16 \mathrm{hPa}$ ) outside the tropics (in the tropics). Thus we test the resulting smoothing error when combining all layers below these thresholds.

For comparison with the limb instruments (e.g., Aura MLS) that do not measure ozone below $250 \mathrm{hPa}$, the layer combination from 250 to $25 \mathrm{hPa}$ (or $16 \mathrm{hPa}$ ) can be used outside of the tropics (in the tropics). Even though SBUV measures ozone down to the ground, the signal significantly reduces for layers below $250 \mathrm{hPa}$ and the amplitude of the $\mathrm{AK}$ below $250 \mathrm{hPa}$ is negligibly small (see Fig. 2). Thus, we also calculate the smoothing error for the layer combinations from 250 to $25 \mathrm{hPa}$ (or $16 \mathrm{hPa}$ ) outside of the tropics (in the tropics). 
The smoothing error for a merged layer $S_{\text {serr }}^{k_{o}, k_{n}}$ can be estimated using the following expression:

$S_{\mathrm{serr}}^{k_{o}, k_{n}}=\sqrt{\sum_{i=k_{0}}^{i=k_{n}} \sum_{j=k_{0}}^{j=k_{n}} \mathbf{S}_{\mathrm{serr}}(i, j)}$,

where $k_{0}$ and $k_{n}$ are indices for the top and bottom layers included in the merged layer. The derivation of this expression is presented in the Supplement.

Figure 7 shows the smoothing error as a function of latitude for several layer combinations. It is very important to note that even when the smoothing error for any individual layer in the troposphere/lower stratosphere is large, the smoothing error for the combined layer is substantially less. The high negative inter-level correlation of errors (offdiagonal elements of $\mathbf{S}_{\text {serr }}$ ) plays a significant role in reducing the merged layer error (see Supplement Fig. S3). The smoothing errors are larger in the tropics compared to the mid and high latitudes. At high latitudes errors are larger in winter and smaller in boreal summer as the SZA changes.

In the narrow tropical zone between $20^{\circ} \mathrm{S}$ and $20^{\circ} \mathrm{N}$, the smoothing errors are about $2-3 \%$ for the surface $-25 \mathrm{hPa}$ and 250-25 hPa layers (see Fig. 7a, c). The smoothing error drops to about $1 \%$ in the tropics when all layers up to $16 \mathrm{hPa}$ are combined (see Fig. 7b, d). If we require the smoothing error for the combined layer to be $\sim 1 \%$ or less ( $1 \sigma$ interval), this condition is satisfied for the layer combinations from the surface (or from $250 \mathrm{hPa}$ ) to $25 \mathrm{hPa}$ outside of the tropics. In the narrow tropical zone between $20^{\circ} \mathrm{S}$ and $20^{\circ} \mathrm{N}$ the upper boundary for the combined layers should be extended up to $16 \mathrm{hPa}$. With caution, users might choose other layer combinations depending on the scientific objectives of the study.

Comparisons with independent measurements in the defined broad layers support the theoretical results presented above. Comparisons of SBUV ozone amounts in the lower stratosphere/troposphere layer with Aura MLS (Kramarova et al., 2013) showed that the standard deviations of the differences between SBUV and MLS mzm measurements in the tropics decreased from $3-4 \%$ for the $250-25 \mathrm{hPa}$ layer to $1 \%$ for the $250-16 \mathrm{hPa}$ layer. Labow et al. (2013) show $\mathrm{a} \pm 5 \%$ agreement between ozone amounts in the surface$25 \mathrm{hPa}$ layer measured by the SBUV and several ozonesonde stations over a $40 \mathrm{yr}$ time period.

\subsection{QBO detection: interpretation of the SBUV smoothing error}

In this section we will discuss a simple interpretation of the SBUV smoothing error by considering again the QBO ozone anomalies in the lower tropical stratosphere. Figure 8 shows the time series of the mzm seasonal anomalies for three individual layers and the combined layer $(250-16 \mathrm{hPa})$ in the equatorial stratosphere. Red lines show the SBUV anomalies and black lines represent Aura MLS anomalies. The shadowed pink areas indicate the $\pm 2 \sigma$ range of the calculated
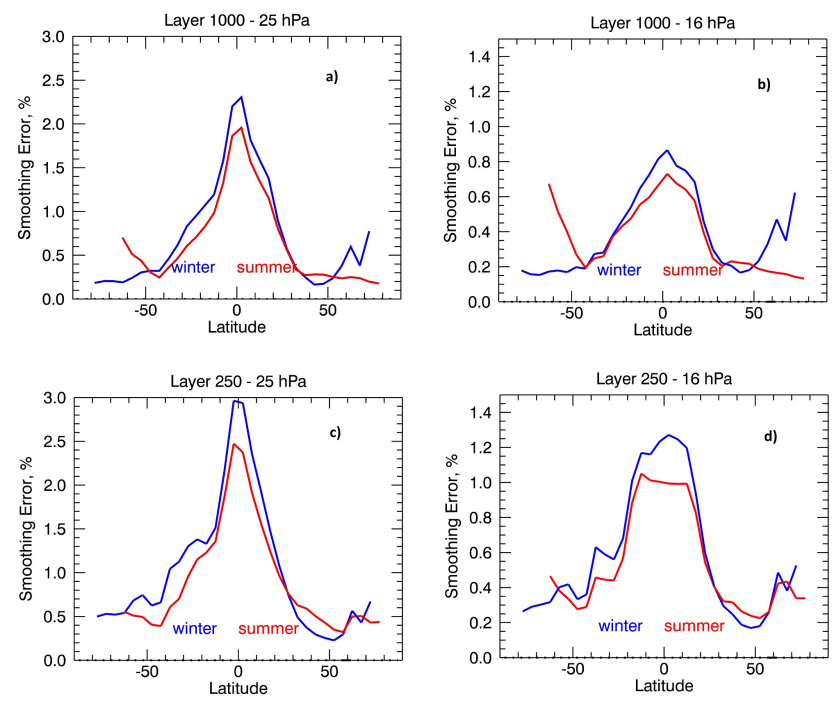

Fig. 7. Smoothing error as a function of latitude for different combinations of layers in the lower stratosphere/troposphere: (a) surface$25 \mathrm{hPa}$; (b) surface-16 hPa; (c) $250-25 \mathrm{hPa}$; and (d) $250-16 \mathrm{hPa}$. Blue lines show errors in winter months (DJF) and red lines errors in summer months (JJA).

SBUV layer smoothing error. At each layer in the lower stratosphere the amplitudes of the ozone anomalies associated with the QBO are of the same order as the SBUV smoothing errors. Thus, the smoothing error can be understood as the limit (or range) of the SBUV sensitivity - if the amplitude of ozone anomalies at a particular layer is less than the corresponding layer smoothing error, the observing system cannot retrieve these anomalies. It is also important to note that the differences between MLS and SBUV anomalies are within the $2 \sigma$ smoothing error bars. This means the instruments are measuring the same ozone profile and the difference between the two retrieval results is indeed due to the SBUV smoothing error. However, when we merge the recommended layers, the SBUV integrated ozone column contains the QBO signal with a proper amplitude and phase (Fig. 8d), and the smoothing error is substantially less than the amplitude of the QBO.

This example uses the tropics to demonstrate the limitation of the SBUV measuring system. Due to its coarse vertical resolution, the SBUV measures a signal from a broad vertical range, and the retrieval algorithm relies on the a priori profiles to distribute the measured signal among individual layers. The SBUV algorithm uses seasonal a priori profiles, which do not contain information about the QBO. The quasiperiodic nature of the QBO and its downward vertical propagation over time make it hard to capture QBO features in a seasonal climatology. The combination of all these factors results in the incorrect vertical distribution of the QBO signal measured by the SBUV and misrepresentation of the amplitude and phase of ozone anomalies at individual layers in the lower tropical stratosphere. 


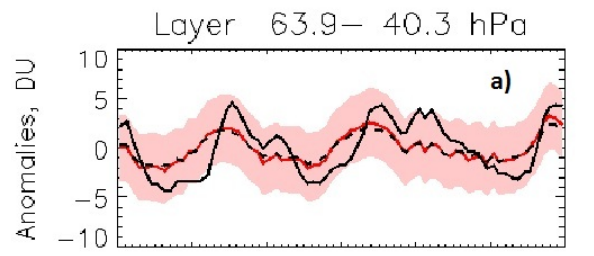

2005200620072008200920102011 Years

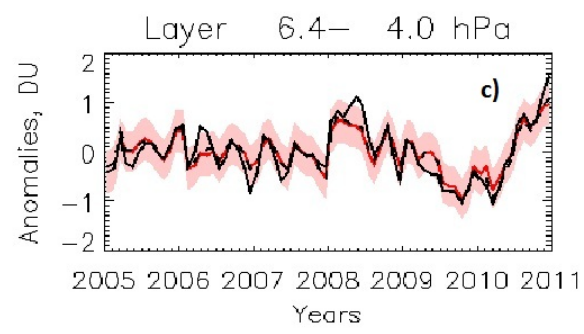

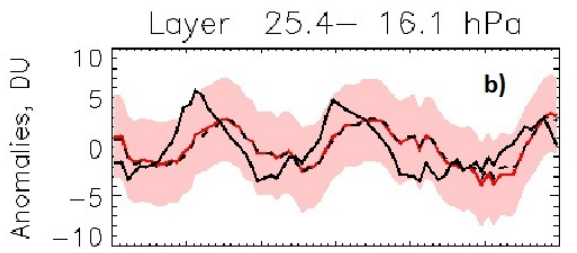

2005200620072008200920102011 Years

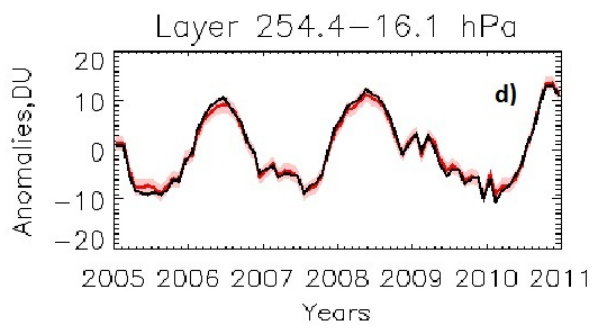

Fig. 8. Time series of the deseasonalized ozone anomalies obtained from SBUV and Aura MLS for several layers in the tropical stratosphere: (a) 63-40 hPa layer; (b) 25-16 hPa layer; (c) 6-4 hPa layer; and (d) 254-16 hPa layer. Red lines show SBUV anomalies along with the corresponding smoothing errors (shadowed pink areas indicate $\pm 2 \sigma$ range). Black lines show MLS anomalies, and black dashed lines indicate convolved MLS anomalies. The $254-16 \mathrm{hPa}$ ozone columns (for both SBUV and MLS) were calculated by simply summing partial ozone columns in six individual layers (layers 4-9).

\section{Conclusions}

In this study we present the methodology used to estimate the smoothing error for SBUV ozone monthly zonal mean profiles. The smoothing error represents the error in the vertical profile due to the limited vertical resolution of the observing system. The smoothing error depends on two parameters - the SBUV averaging kernels that characterize the retrieval algorithm and its vertical resolution, and the covariance matrix that describes the natural variability of ozone fields. To estimate the smoothing error for the monthly zonal mean profiles, we constructed covariance matrices that characterize the inter-annual ozone variability for each latitude bin by using Aura MLS and sonde monthly zonal mean profiles over a 6 yr time period.

Between the 10 and $1 \mathrm{hPa}$ layers the smoothing error is about $1 \%$. Outside of this vertical range the smoothing errors increase to as high as $15-20 \%$ in the troposphere. The smoothing errors for total ozone are much smaller, mostly less than $0.5 \%$. The smoothing errors for the SBUV monthly mean time series over any particular location (for example, overpasses over ground-based stations) can be considered to be the same order of magnitude as the monthly zonal mean errors for the corresponding latitude bin.

The smoothing effect should be taken into account when analyzing SBUV ozone data at individual layers. When several ozone layers are merged together in the lower stratosphere and troposphere, the corresponding smoothing error decreases. We recommend using the following layer combinations to reduce the smoothing error to $1 \%$ or less: surface $-25 \mathrm{hPa}$ or $250-25 \mathrm{hPa}$ everywhere outside of the narrow tropical zone from $20^{\circ} \mathrm{S}$ to $20^{\circ} \mathrm{N}$. In these tropical latitudes we recommend merging all layers up to $16 \mathrm{hPa}$.

We found that the amplitude of the QBO ozone anomalies at any individual layer in the lower tropical stratosphere are of the same order as the SBUV layer smoothing error, meaning that the observing system cannot properly retrieve the signal at individual layers. The smoothing error can be understood as the limit (or range) of the SBUV sensitivity. If the amplitude of ozone anomalies at a particular layer is less than the corresponding layer smoothing error, the observing system cannot properly retrieve these anomalies. This explains why the SBUV algorithm produces an incorrect phase and amplitude of the QBO ozone anomalies at any individual layer and misses the vertical downward propagation of the QBO signal. However, we showed that the SBUV accurately captures both the amplitude and phase of the QBO signal in the thick $250-16 \mathrm{hPa}$ layer.

The implication of this study is that the SBUV observing system can be used to derive long time series of ozone measurements if one carefully considers the limitations of the retrieved ozone profiles imposed by the limitations of the vertical resolution of the measurements in the lower stratosphere and troposphere. We have suggested combinations of the traditionally derived layer amounts that lower the smoothing error and give an adequate representation of the ozone profiles measured by SBUV instruments. Use of these layer combinations are recommended for the proper interpretation of the SBUV data, including ozone trend analysis and model comparisons. Accordingly, a merged ozone data set from the SBUV instrument series for trend analysis studies has been released in the recommended layer combinations (http: //acdb-ext.gsfc.nasa.gov/Data_services/merged/index.html). 


\section{Supplementary material related to this article is available online at: http://www.atmos-meas-tech.net/6/ 2089/2013/amt-6-2089-2013-supplement.pdf.}

Acknowledgements. The authors greatly appreciate the work of all members of the SBUV science team. We also acknowledge the work of the Aura MLS science team for their high quality satellite ozone data set. We would like to thank two anonymous referees for their thoughtful comments that helped us to improve the manuscript.

Edited by: J. Urban

\section{References}

Baldwin, M. P., Gray, L. J., Dunkerton, T. J., Hamilton, K., Haynes, P. H., Randel, W. J., Holton, J. R., Alexander, M. J., Hirota, I., Horinouchi, T., Jones, D. B. A., Kinnersley, J. S., Marquardt, C., Sato, K., and Takahashi, M.: The Quasi-Biennial Oscillation, Rev. Geophys., 39, 179-229, doi:10.1029/1999RG000073, 2001.

Bhartia, P. K., McPeters, R. D., Flynn, L. E., Taylor, S., Kramrova, N. A., Frith, S., Fisher, B., and DeLand, M.: Solar Backscatter UV (SBUV) total ozone and profile algorithm, Atmos. Meas. Tech. Discuss., 5, 5913-5951, doi:10.5194/amtd-5-5913-2012, 2012.

DeLand, M. T., Taylor, S. L., Huang, L. K., and Fisher, B. L.: Calibration of the SBUV version 8.6 ozone data product, Atmos. Meas. Tech., 5, 2951-2967, doi:10.5194/amt-5-2951-2012, 2012.

Froidevaux, L., Jiang, Y. B., Lambert, A., Livesey, N. J., Read, W. G., Waters, J. W., Browell, E. V., Hair, J. W., Avery, M. A., McGee, T. J., Twigg, L. W., Sumnicht, G. K., Jucks, K. W., Margitan, J. J., Sen, B., Stachnik, R. A., Toon, G. C., Bernath, P. F., Boone, C. D., Walker, K. A., Filipiak, M. J., Harwood, R. S., Fuller, R. A., Manney, G. L., Schwartz, M. J., Daffer, W. H., Drouin, B. J., Cofield, R. E., Cuddy, D. T., Jarnot, R. F., Knosp, B. W., Perun, V. S., Snyder, W. V., Stek, P. C., Thurstans, R. P., and Wagner, P. A.: Validation of Aura Microwave Limb Sounder stratospheric ozone measurements, J. Geophys. Res. 113, D15S20, doi:10.1029/2007JD008771, 2008.
Hollandsworth, S. M., Bowman, K. P., and McPeters, R. D.: Observational study of the quasi-biennial oscillation in ozone, J. Geophys. Res., 100, 7347-7361, doi:10.1029/95JD00193, 1995.

Kramarova, N. A., Frith, S. M., Bhartia, P. K., McPeters, R. D., Taylor, S. L., Fisher, B. L., Labow, G. J., and DeLand, M. T.: Validation of ozone monthly zonal mean profiles obtained from the version 8.6 Solar Backscatter Ultraviolet algorithm, Atmos. Chem. Phys., 13, 6887-6905, doi:10.5194/acp-13-6887-2013, 2013.

Labow, G. J., McPeters, R. D., Bhartia, P. K., and Kramarova, N.: A Comparison of 40 years of SBUV Measurements of Column Ozone with Data from the Dobson/Brewer Network, J. Geophys. Res. Atmos., 118, 7370-7378, doi:10.1002/jgrd.50503, 2013.

Liu, X., Bhartia, P. K., Chance, K., Froidevaux, L., Spurr, R. J. D., and Kurosu, T. P.: Validation of Ozone Monitoring Instrument (OMI) ozone profiles and stratospheric ozone columns with Microwave Limb Sounder (MLS) measurements, Atmos. Chem. Phys., 10, 2539-2549, doi:10.5194/acp-10-2539-2010, 2010.

Livesey, N. J., Read, W. G., Froidevaux, L., Lambert, A., Manney, G. L., Pumphrey, H. C., Santee, M. L., Schwartz, M. J., Wang, S., Cofeld, R. E., Cuddy, D. T., Fuller, R. A, Jarnot, R. F., Jiang, J. H., Knosp, B. W., Stek, P. C., Wagner, P. A., and Wu, D. L.: Earth Observing System (EOS) Aura Microwave Limb Sounder (MLS) Version 3.3 Level 2 data quality and description document, Tech. Rep. NASA JPL D-33509, NASA Jet Propul. Lab., Pasadena, California, available at: http://mls.jpl.nasa.gov, 162 pp., 2011.

McPeters, R. D. and Labow, G. J.: Climatology 2011: An MLS and sonde derived ozone climatology for satellite retrieval algorithms, J. Geophys. Res., 117, D10303, doi:10.1029/2011JD017006, 2012.

McPeters, R. D., Bhartia, P. K., Haffner, D., Labow, G. J., and Flynn, L.: The v8.6 SBUV Ozone Data Record: An Overview, J. Geophys. Res. Atmos., 118, 8032-8039, doi:10.1002/jgrd.50597, 2013.

Rodgers, C. D.: Characterization and error analysis of profiles retrieved from remote sounding measurements, J. Geophys. Res., 95, 5587-5595, doi:10.1029/JD095iD05p05587, 1990.

Rodgers, C. D.: Inverse methods for atmospheric sounding, Theory and Practice; Series on Atmospheric, Oceanic and Planetary Physics, Vol. 2, World Scientific, 2000.

Rodgers, C. D. and Connor, B. J.: Intercomparison of remote sounding instruments, J. Geophys. Res., 108, 4116, doi:10.1029/2002JD002299, 2003. 